\title{
DESCRIÇÃO HISTOLÓGICA DE ÓRGÃOS VISCERAIS DE TILÁPIA (Oreochromis niloticus)
}

Stéphanie Silva Nunes de Almeida ${ }^{1}$, Gabriella Canedo Costa1 ${ }^{1}$ Fernanda Gomes de Paula $^{2}$, Regiani Nascimento Gagno Porto ${ }^{3}$, Ana Paula Iglesias Santin ${ }^{3}$

1 Acadêmica em Medicina Veterinária, PIVIC em Iniciação Científica (regianiporto@hotmail.com), Escola de Veterinária e Zootecnia, Universidade Federal de Goiás, Goiânia, Goiás, Brasil.

2.Professor Adjunto, Departamento de Produção Animal, Escola de Veterinária e Zootecnia, Universidade Federal de Goiás, Goiânia, Goiás, Brasil, CEP: 74.690-900 ferdepaulazootec@yahoo.com.br,

3 Professor Adjunto, Setor de Patologia Animal, Departamento de Medicina Veterinária, Escola de Veterinária e Zootecnia, Universidade Federal de Goiás, Goiânia, Goiás, Brasil, CEP 74.690-900, (62) 3521-1665.

\section{Recebido em: 08/09/2015 - Aprovado em: 14/11/2015 - Publicado em: 01/12/2015} DOI: http://dx.doi.org/10.18677/Enciclopedia_Biosfera_2015_247

\begin{abstract}
RESUMO
A produção de peixes nativos tem apresentado um crescimento significativo, no Brasil. O clima favorece o cultivo da tilápia no país, sendo uma carne bastante apreciada no mundo todo, possuindo um sabor leve e uma textura macia. Nos sistemas de produção, os animais sofrem um estresse contínuo decorrente de um manejo incorreto, seja nutricional ou sanitário. Sendo assim, qualquer comprometimento de estruturas e órgãos interferindo em sua função reflete diretamente na saúde, consequentemente há um menor ganho de peso, e a atividade deixa de ser lucrativa. Deste modo, o presente trabalho teve como objetivo o conhecimento da histologia normal de alguns órgãos viscerais da tilápia. Foram utilizados 20 exemplares oriundos da Piscicultura do Departamento de Produção Animal da Escola de Veterinária e Zootecnia da Universidade Federal de Goiás (EVZ/UFG). O estudo histológico permitiu a descrição detalhada dos diversos órgãos estudados, coração, brânquias, estômago, intestino, baço e hepatopâncreas. A caracterização microscópica destes órgãos propiciou informações que auxiliarão em estudos relacionados a distúrbios patológicos e de manejo.
\end{abstract}

PALAVRAS-CHAVE: Brânquias, hepatopâncreas, microscopia, peixe

\section{HISTOLOGICAL DESCRIPTION OF TILAPIA VISCERAL ORGANS (Oreochromis niloticus)}

\begin{abstract}
The native fish production has shown significant growth in Brazil. Climate further tilapia's cultivation in the country, its meat is valued around the world, having a mild flavor and a soft texture. In production systems, animals suffer continuous stress due incorrect handling, either nutritional or health. Thus, any structures and organs damage can disturbs its function with directly returns on health, therefore there is less weight gain and business is no more gainful. This study aimed to learn more
\end{abstract}


about normal histology of some tilapia visceral organs. Twenty samples were used; they came from Animal Production Department of Veterinary and Animal Science School/ Goiás Federal University (EVZ / UFG). The histological study allowed some organs detailed description, like heart, gills, stomach, intestine, spleen and hepatopancreas. Microscopic characterization of these tissues led to information that will help in studies related to pathological disorders and management.

KEYWORDS: Gills, hepatopancreas, microscopy, fish

\section{INTRODUÇÃO}

A produção de peixes nativos tem apresentado um crescimento significativo, no Brasil. Acredita-se que esta produção deverá crescer muito mais nos próximos anos, principalmente com a expansão da piscicultura nos estados da região CentroOeste, que em 2013 foi o principal produtor, participando em 26,8\% da produção nacional, sendo a tilápia, a espécie mais criada com $43,1 \%$ do total de pescados produzidos (COLPANI, 2014).

Segundo o Ministério da Pesca e Aquicultura, entre 2003 e 2013, ou seja, em uma década, o consumo nacional de pescado aumentou mais de 100\% (BRASIL, 2014). A Organização Mundial da Saúde (OMS) recomenda um consumo de 12 $\mathrm{kg} / \mathrm{hab} / \mathrm{ano}$ (FAO, 2014). Enquanto a média de consumo per capita, no Brasil, era de aproximadamente 9,75kg/hab/ano 2010 (BRASIL, 2010), em 2013 o consumo médio por habitante/ano aumentou para $14,5 \mathrm{Kg}$ (BRASIL, 2014). A tendência é que o consumo interno de pescado continue a crescer nos próximos anos.

O clima favorece o cultivo da tilápia no Brasil, uma vez que é uma carne bastante apreciada no mundo todo, possuindo um sabor leve e uma textura macia. Segundo os dados do MPA a produção nacional de tilápias de 155.450 toneladas em 2010 (BRASIL, 2010) passou a 210.000 toneladas em 2014 (BRASIL, 2014). Portanto, como ocorre na patologia de todos os sistemas, os aspectos morfológicos fundamentais dos tecidos/órgãos devem ser conhecidos para que suas alterações possam ser mais compreendidas, permitindo que o patologista esteja familiarizado com a estrutura normal da espécie estudada. (CAVICHIOLO, 2009; SIDONIO et al., 2012).

Nos sistemas de produção, os animais sofrem um estresse contínuo decorrente de um manejo incorreto, seja nutricional ou sanitário. Sendo assim, qualquer comprometimento de estruturas e órgãos interferindo em sua função reflete diretamente na saúde, consequentemente há um menor ganho de peso, e a atividade deixa de ser lucrativa (DINIZ \& HONORATO, 2012).

Apesar de todo crescimento produtivo, ainda há necessidade de se investir na ampliação de dados relacionados ao aspecto sanitário da criação. Em virtude da falta de conhecimento e da ausência de assistência técnica, surgem problemas de manejo que podem levar ao desenvolvimento de doenças, maior mortalidade, problemas de higiene, entre outros (FRANÇA \& PIMENTA, 2012; SIDONIO et al., 2012).

O presente estudo objetivou a descrição histológica das brânquias, coração, hepatopâncreas, baço, estômago e intestino de tilápias, visando conhecer os aspectos normais histológicos destes órgãos, para que em um futuro próximo, seja útil na identificação de lesões causadas por diversos microrganismos e assim, também, na busca por soluções contra tais enfermidades. 


\section{MATERIAL E MÉTODOS}

O experimento foi conduzido na Piscicultura do Departamento de Produção Animal e no Setor de Patologia Animal da Escola de Veterinária e Zootecnia da Universidade Federal de Goiás (EVZ/UFG), no período de agosto de 2013 a junho de 2014. Foram avaliadas vísceras da cavidade corporal de tilápias, oriundas do criatório localizado no Setor de Piscicultura da Escola de Veterinária e Zootecnia da UFG. Foram utilizados 20 exemplares da espécie Oreochromis niloticus com peso médio de 250 gramas que seriam destinados ao comércio e designados para consumo humano, por isso, não houve necessidade de aprovação pela Comissão de Ética no Uso de Animais da UFG (CEUA/UFG).

O primeiro passo foi a coleta dos animais nos criatórios, os quais foram eutanasiados com o anestésico Eugenol, na dosagem de $0,75 \mathrm{~mL}$ na proporção de 1:9 de álcool comum em 10 litros de água. Utilizou-se água gelada para adiar o tempo de autólise das células. A abertura da cavidade foi realizada no próprio criatório, pela técnica apresentada no guia de necropsia de MARTINS (2011).

A evisceração foi realizada no mesmo local, onde foram colhidos fragmentos dos seguintes órgãos: brânquias, hepatopâncreas, baço, estômago, intestino e coração. Estes foram acondicionados em recipientes de boca larga, devidamente identificados, contendo solução fixadora aquosa de formol a $10 \%$, neutro e tamponado.

O material colhido permaneceu 48 horas submerso no fixador para adequada preservação das amostras. Na sequência, este foi processado e incluído em parafina de acordo com as técnicas rotineiras do Laboratório de Histopatologia, Setor Patologia, EVZ/UFG. Foram confeccionados cortes de $3 \mu \mathrm{m}$, distendidos sobre lâminas histológicas e corados pela técnica de Hematoxilina e Eosina (LUNA, 1968).

Para a leitura das lâminas utilizou-se o microscópio óptico de campo claro, com aumentos de 5x,10x e 40x, onde identificou-se o órgão e em seguida realizouse a descrição histológica minuciosamente. Desta forma, o presente trabalho teve como finalidade apenas a descrição histológica, não sendo pertinente realização de estudo estatístico.

\section{RESULTADOS E DISCUSSÃO}

No coração verificou-se, em relação às câmaras cardíacas, que o átrio possuía maior lúmen que o ventrículo. No entanto, ambos eram compostos pelo mesmo tipo de tecido, o músculo estriado cardíaco, o qual possuía uma fina camada de aspecto compacto e o restante esponjoso, apresentando feixes musculares dispostos em diversas direções (Figura $1 \mathrm{~A}$ ). $\mathrm{O}$ órgão estava envolvido por discreto epicárdio, que consistia em delgada camada de tecido conjuntivo frouxo e epitélio pavimentoso simples. Internamente, era revestido pelo endocárdio, composto por epitélio pavimentoso simples. Notou-se a presença de uma estrutura diferenciada, denominada bulboarterioso, composto por fibras musculares lisas, orientadas em várias direções e sentidos e tecido conjuntivo elástico (Figura 1B). Este ainda era circundado por fina camada de tecido conjuntivo frouxo e revestido por epitélio pavimentoso simples, possuindo uma estrutura semelhante ao epicárdio do coração.

Características semelhantes às descritas neste trabalho também foram notadas por MUMFORD et al. (2007) e GENTEN et al. (2009), que mencionaram a parede ventricular mais espessa do que o átrio, com um lúmen menor e presença de epicárdio. Além disso, as orientações dos feixes de fibras musculares e suas características também foram citadas por MORRISON et al. (2006). As observações realizadas no bulboarterioso deste trabalho foram igualmente citadas por 
MUMFORD et al. (2007) e GENTEN et al. (2009), apresentando a mesma constituição.
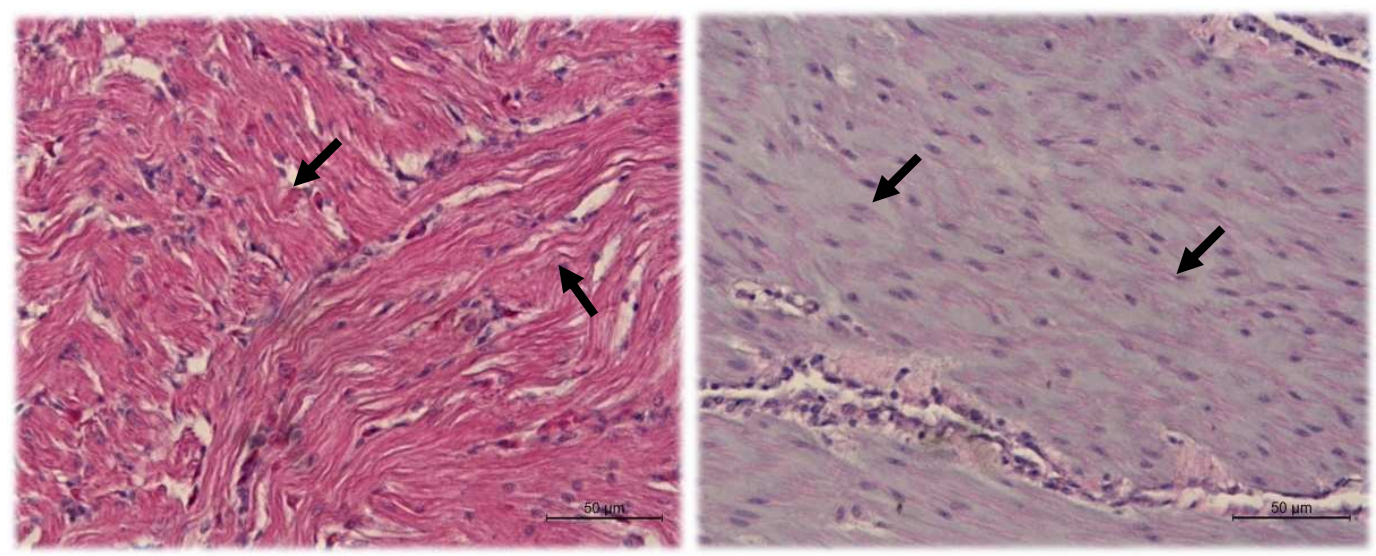

FIGURA 1: Fotomicrografia do coração de tilápia (Oreochromis niloticus), A) Fibras musculares estriadas cardíacas em diversas direções (setas). Bulboarterioso do coração com fibras musculares lisas evidentes (setas). HE 100x.

As brânquias eram compostas por lamelas primárias e secundárias, sendo esta última perpendicular à primeira (Figura 2). Eritrócitos estavam presentes em ambas as lamelas para ser oxigenado. Epitélio pavimentoso simples, com células pilastras encontravam-se localizados nas lamelas secundárias. Observaram-se também células cloreto (chloride cells) com citoplasma ligeiramente eosinofílico, núcleo central e basofílico, sendo encontradas, principalmente, na base das lamelas secundárias.

Neste trabalho as brânquias foram descritas de forma semelhante às citações de MUMFORD et al. (2007) e GENTEN et al. (2009), no entanto, estes últimos mencionam a presença de células caliciformes, as quais não foram encontradas nas amostras estudadas.

Nas vilosidades do estômago foi possível observar que a mucosa era revestida por epitélio cilíndrico simples constituído por células altas e delgadas, núcleo alongado e citoplasma de coloração eosinofílica. Havia a presença de glândulas circulares alveolares formadas por células mucosas localizadas na base do epitélio. Abaixo, na lâmina própria, estavam presentes glândulas tubulares, serosas, com citoplasma eosinofílico e núcleo oval basofílico (Figura 3). A muscular da mucosa, por sua vez, era bem visível e composta por músculo liso. A submucosa possuía tecido conjuntivo frouxo e a camada muscular era composta por tecido muscular estriado esquelético e subdividida em duas porções: a circular interna, camada mais espessa, e a transversal externa que correspondia, aproximadamente, a $20 \%$ da camada circular. Por fim, a camada serosa, composta por tecido conjuntivo frouxo e epitélio pavimentoso simples. 


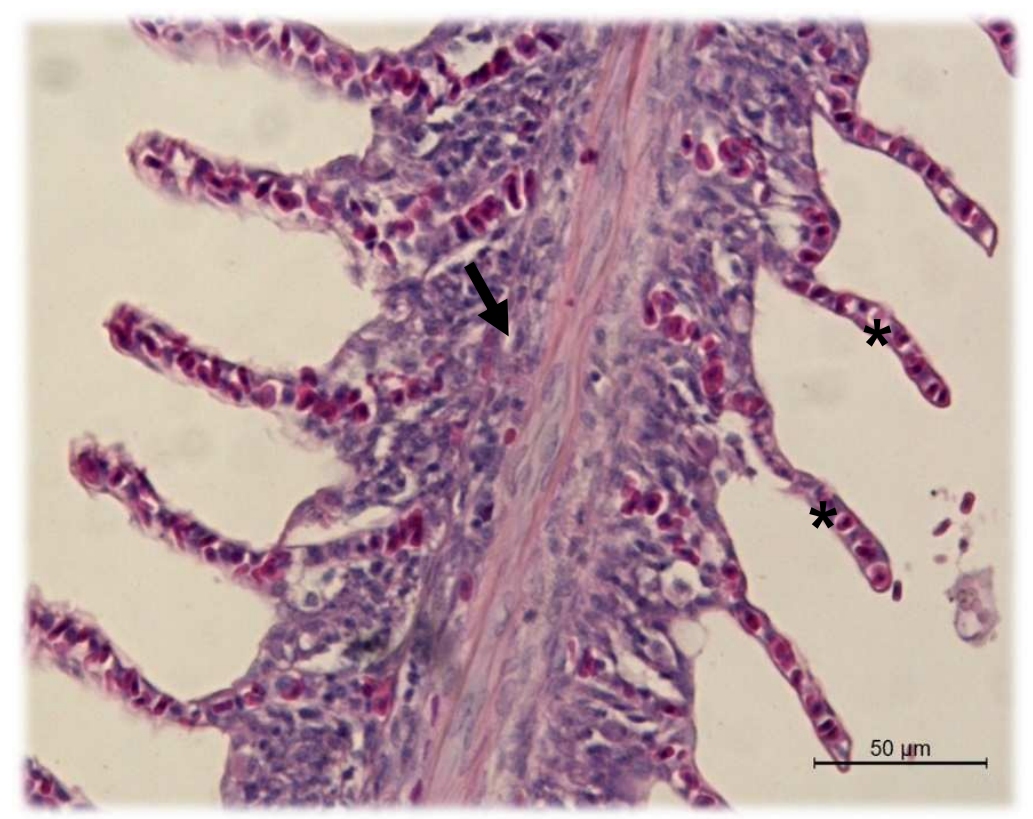

FIGURA 2: Fotomicrografia da brânquia de tilápia (Oreochromis niloticus), evidenciando lamela primária (seta preta) e lamela secundária (asteriscos). HE 100x.

O epitélio do estômago foi descrito de forma semelhante por MORRISON et al. (2006) e GENTEN et al. (2009), que também mencionaram a presença de glândulas circulares alveolares, bem como a presença de glândulas tubulares na lâmina própria, no entanto o mesmo acrescentou em relato a presença de grânulos eosinofílicos na submucosa e músculo liso na constituição da camada muscular, em Oreochromis niloticus, o que talvez seja devido a presença de algum agente parasitário, embora este fato não tenha sido abordado pelos autores. Já MENDOZA et al. (2013) que trabalharam com Piaractus brachypomus, observaram músculo estriado esquelético na composição da camada muscular como verificado no presente trabalho.

O intestino possuía vilosidades compostas por células epiteliais cilíndricas simples, altas, com citoplasma de coloração eosinofílica e núcleo alongado, basofílico e predominantemente central. Havia também a presença de muitas células caliciformes e vacúolos intracitoplasmáticos (Figura 4). A lâmina própria/submucosa era composta por tecido conjuntivo frouxo. Já a camada muscular lisa, possuía mais internamente uma porção circular espessa e externamente camada transversal mais delgada. A camada serosa era típica.

A descrição do epitélio da mucosa do presente estudo foi igualmente mencionado por GENTEN et al. (2009), HONORATO et al. (2011) e MENDOZA et al. (2013). Já ARANDAS et al. (2009) verificaram semelhança com a lâmina própria e a camada muscular, bem como em relação a enterócitos com borda em escova (Figura 4). GENTEN et al. (2009) ainda descreveram a existência de eosinófilos e tecido linfoide na lâmina própria e submucosa, elementos não observados neste estudo. Já SILVA et al. (2005), estudaram Steindachnerina notonota, notaram que a camada muscular era muito delgada a ponto de ser quase imperceptível. 


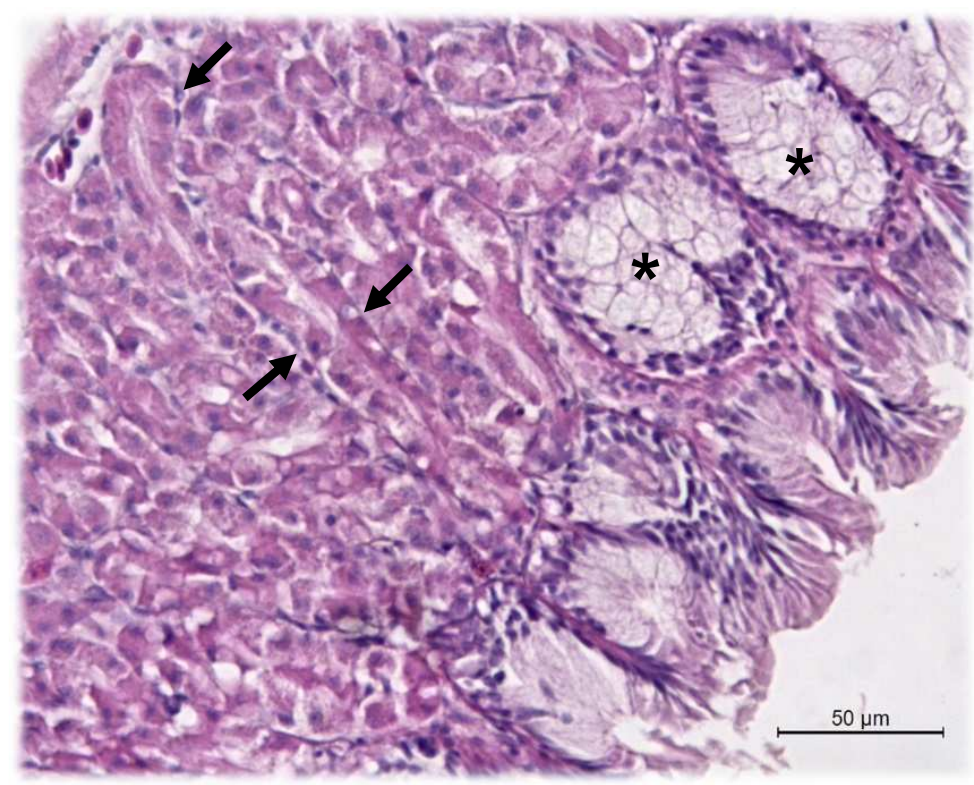

FIGURA 3: Fotomicrografia do estômago de tilápia (Oreochromis niloticus), com glândulas circular alveolar mucosa (asteriscos) e tubular serosa (setas pretas). HE 100x.

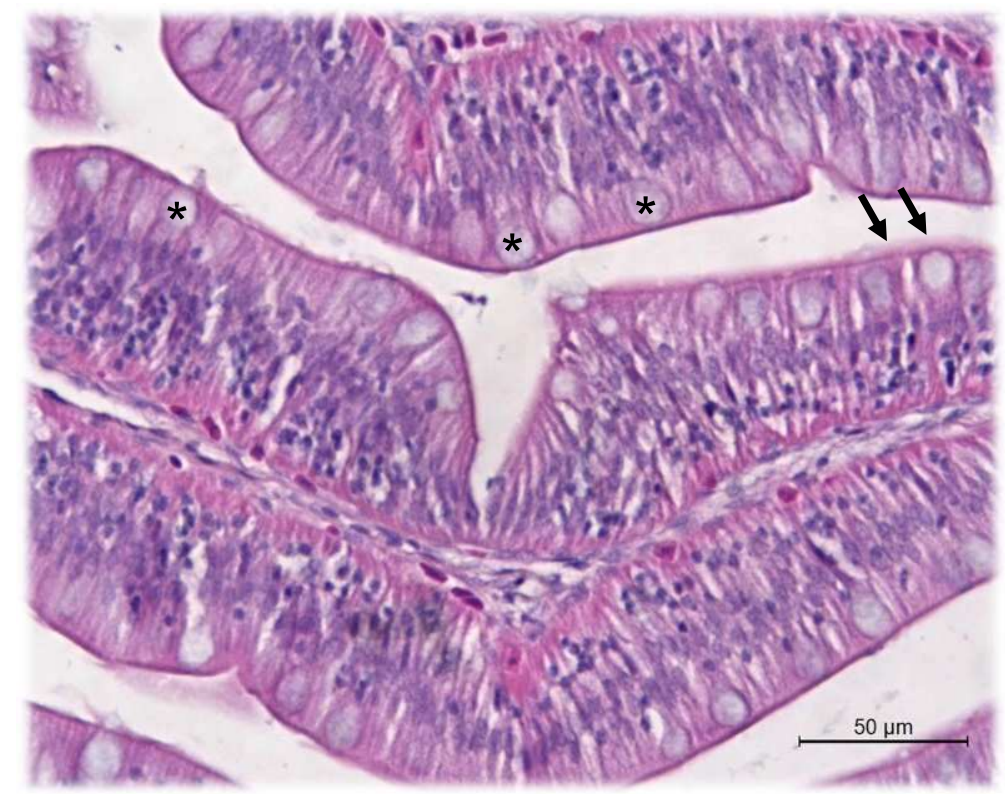

FIGURA 4: Fotomicrografia do intestino de tilápia (Oreochromis niloticus), com vilosidade apresentando célula caliciforme (asteriscos) e borda em escova (setas pretas). HE 100x.

O baço da tilápia era histologicamente composto pela polpa branca e polpa vermelha, as quais estavam difusas e sem definição, diferentemente do que se observa no baço dos mamíferos, em que a polpa branca e polpa vermelha são bem delimitadas. Havia escasso tecido conjuntivo denso, com coloração clara. Observouse também a presença de melanomacrófagos (Figura 5). 
As polpas brancas e vermelhas não se apresentavam tão definidas, possuindo uma forma mais difusa, além disso, o tecido de sustentação do parênquima esplênico era escasso e pouco proeminente assim como mencionado por MUMFORD et al (2007) e GENTEN et al. (2009), que igualmente observaram a presença de melanomacrófagos. GENTEN et al. (2009), no entanto, relataram a presença de bainhas periarteriais de macrófagos e fibrócitos, formados na extremidade de arteríolas esplênicas, no entanto este achado não foi observado no presente estudo.

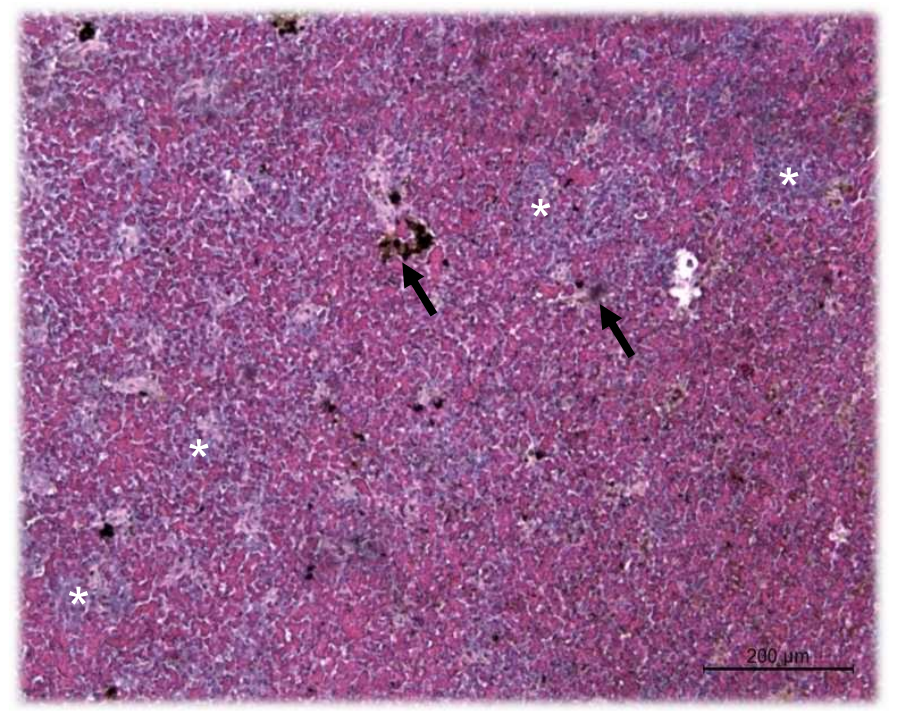

FIGURA 5: Fotomicrografia do baço de tilápia (Oreochromis niloticus), com presença de melanomacrófagos (seta preta) e polpa branca difusa (asteriscos). HE 50x.

Algumas espécies de peixes, diferentemente dos mamíferos, possuem hepatopâncreas, isto é, o fígado e o pâncreas fazem parte de um mesmo órgão. $E$ trata-se de um órgão relativamente grande, assim como nos mamíferos. No entanto, na análise histológica deste órgão, não se observou o padrão trabecular e a tendência dos hepatócitos em formar cordões. Os hepatócitos eram poliédricos, com citoplasma de coloração eosinofílica clara, núcleo central e esférico e nucléolo evidente. Estas células ainda possuíam vacúolos de glicogênio no citoplasma.

No hepatopâncreas também se observou a presença de células de Kupffer e de veia terminal hepática. Os ductos biliares possuíam epitélio cilíndrico simples, com células altas, citoplasma de coloração eosinofílica e núcleo oval basofílico localizados na base das células, sendo acompanhados por arteríolas e envolvidos por tecido conjuntivo frouxo (Figura 6A).

A porção pancreática apresentou-se distribuída por toda a extensão do fígado. No entanto, apenas a porção exócrina foi identificada, com células acinares, citoplasma tendendo à coloração basofílica e núcleo oval basofílico. Estas células organizavam-se em pequenos grupamentos circulares, com ductos pancreáticos ao redor. Foi possível a visualização de grânulos de zimogênio, os quais apresentaramse eosinofílicos (Figura 6B). Por fim, havia uma camada serosa circundando o órgão, composta por tecido conjuntivo frouxo e epitélio pavimentoso simples. 
A associação do fígado ao pâncreas, denominado hepatopâncreas também foi mencionada por MUMFORD et al. (2007), no entanto MENDOZA et al. (2013) acreditam que o fígado e o pâncreas não sofrem fusão, sendo a nomenclatura mais adequada pâncreas intra-hepático. MUMFORD et al.(2007), GENTEN et al.(2009) e MENDOZA et al. (2013), observaram características semelhantes às verificadas em Oreochromis niloticus do presente estudo. Já GENTEN et al. (2009) não notaram a presença de células de Kupffer, diferentemente do descrito nos exemplares deste experimento.

Em relação ao pâncreas, MUMFORD et al. (2007), GENTEN et al. (2009), e MENDOZA et al. (2013) também mencionaram duas porções distintas, isto é, o pâncreas exócrino e o endócrino, estando 0 pâncreas endócrino circundando 0 exócrino, formando ilhotas de Langerhans, entretanto não foi visualizada esta porção do pâncreas nos cortes histológicos realizados. GENTEN et al. (2009) notaram ainda que o pâncreas exócrino está distribuído não só pelo fígado, como também pode ser encontrado no mesentério e adipócitos, mas no presente estudo, não verificou-se a dispersão do pâncreas nestes últimos tecidos, talvez devido ao órgão apresentar tamanho bastante reduzido, o mesmo não tenha sido notado no momento da colheita das estruturas.

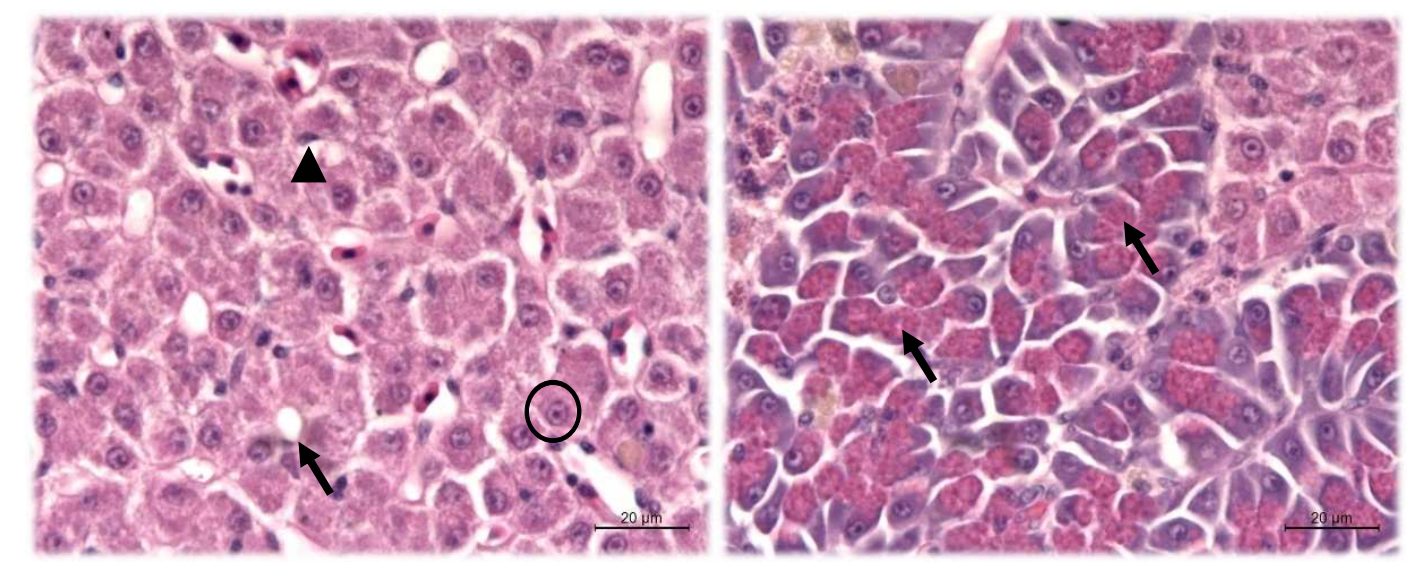

FIGURA 6: Fotomicrografia do hepatopâncreas de tilápia (Oreochromis niloticus). A) Hepatócito com nucléolo evidente (círculo), canalículo biliar (seta preta) e célula de Kupffer (cabaça de seta). B) Porção exócrina do pâncreas, com grânulos de zimogênio eosinofílicos evidentes (setas). HE 200x.

\section{CONCLUSÃO}

O estudo histológico, dos diversos órgãos viscerais das tilápias, permitiu o acréscimo de novos conhecimentos bem como a consolidação de considerações observadas em outros estudos realizados não só nesta espécie, mas também em outras. Portanto, esta caracterização microscópica propiciou informações que auxiliarão em trabalhos relacionados a distúrbios patológicos e de manejo, facilitando o desenvolvimento da piscicultura na região Centro-Oeste. 


\section{REFERÊNCIAS}

ARANDAS, J. K. G.; LUDCKE, M. C. M. M; SANTOS, E. L.; WAMBACH, X. F.; ARANDAS, M. J. G.; XAVIER, T. C.; LIMA, M. R.; LIMA, M. B. Análise histológica do intestino delgado da Tilápia do Nilo (Oreochromis niloticus). 2009, Disponível em: <http://www.eventosufrpe.com.br/jepex2009/cd/resumos/R07641.pdf>. Acesso em:24 jun.2015.

BRASIL. Ministério da Pesca e Aquicultura, 2010. Boletim estatístico da pesca e aquicultura, Brasil 2010. Disponível em: <http://www.mpa.gov.br/files/docs/Informa coes_e_Estatisticas/Boletim\%20Estat\%C3\%ADstico\%20MPA\%202010.pdf>. Acesso em: 10 ago. 2015

BRASIL. Ministério da pesca e aquicultura. Potencial brasileiro, 2014. Online. Disponível em: <http://www.mpa.gov.br/index.php/aquicultura/potencial-brasileiro>. Acesso em 20 ago. 2015

CAVICHIOLO, F. Histologia: ferramenta relevante para estudos em peixes cultivados. In.: OLIVEIRA, A. T.; MARIA, A. N.; GOMES, A. L. S.; VARELLA, A. M. B.; HACKBARTH, A.; MACCHI, B. M.; BALDISSEROTTO, B.; CAVERO, B. A. S.; DOPAZO, C. P.; QUINTANA, C. F.; et al. Manejo e sanidade de peixes em cultivo. Macapá: EMBRAPA, 2009. Cap 23, p. 602-624. Disponível em: < http://projetopacu.com.br/public/paginas/203-livro-manejo-e-sanidade-de-peixes-emcultivo.pdf>. Acesso em 20 ago.2015.

COLPANI PISCICULTURA. Região Centro-Oeste lidera produção de peixes em cativeiro com $\mathbf{4 3 , 1 \% ,} 2014 . \quad$ Disponível em: $<$ http://www.grupoaguasclaras.com.br/regiao-centro-oeste-lidera-producao-depeixes-em-cativeiro-com-431>.Acesso em 24 ago. 2015.

DINIZ, N. M.; HONORATO, C. A. Algumas alternativas para diminuir os efeitos do estresse em peixes de cultivo - revisão. Arquivos de Ciência Veterinária e Zoologia UNIPAR, v. 15, n. 2, p. 149-154, 2012.

FOOD AND AGRICULTURE ORGANIZATION OF THE UNITED NATIONS. The State of WorldFisheries and Aquaculture. Opportunities annd challenges. FAO ROME, $\quad$ p. 1-243, 2014. Disponível em: <http://www.fao.org/fishery/publications/sofia/en>. Acesso em: 15 mai 2015.

FRANÇA, I.; PIMENTA, P.P.P. A viabilidade da piscicultura para o pequeno produtor de Dourados. Comunicação \& Mercado/UNIGRAN - Dourados - MS, v.01, n.01, p. 36-51, 2012.

GENTEN, F.; TERWINGHE, E.; DANGUY, A. Atlas of fish histology. Science publishers, Enfield, USA, 2009. 223p.

hONORATO, C.; CRUZ, C.; CARNEIRO, D. J.; MACHADO, M. R. F. Histologia e histoquímica do intestino anterior de tilápia do Nilo (Oreochromis niloticus) alimentadas com dietas contendo silagem de peixe. Brazilian Journal of Veterinary. Research and Animal Science, v.48, n.4, p.281-288, 2011. 
LUNA, L. G. Manual of Histology Staining Methods of the Armed Forces. Institute of Pathology, third ed. McGraw-Hill, Nova lorque, USA, 1968. 258 p.

MARTINS, L. A necropsia em peixes. 2011. Disponível em: <http://hdl.handle.net/10174/4279>. Acesso em: 24 mai. 2015.

MENDOZA, M. Á. R; CORREDOR, J. C.; HURTADO, C. S. R. Estudio histológico del sistema digestivo en diferentes estadios de desarrollo de la cachama blanca (Piaractus brachypomus). Revista de Medicina Veterinária, n.25, p. 21-38, 2013.

MORRISON, C.M.; FITZSIMMONS, K.; WRIGHT JR, J.R. Atlas of Tilapia Histology. The World Aquiculture Society, 2006, 96p.

MUMFORD, S.;HEIDEL, J.; SMITH, C.; MORRISON, J.; MACCONELL, B.; BLAZER, V. Normal histology.In: MORRISON, J. Fish histology and histopathology. USFWS-NCTC, 2007. Disponível em: <http://training.fws.gov/resources/courseresources/fish-histology/Fish_Histology_Manual_v4.pdf>. Acesso em: 24 ago.2015

SIDONIO, L.; CAVACNTI, I.; CAPANEMA, L.; MORCH, R.; AGALHAES, G.; LIMA, J.; BRUNS, V.; JUNIOR, A.J.A.; MUNGIOLI, R. Panorama da aquicultura no Brasil: desafios e oportunidades. BNDES Setorial, n.35, p.421-463, 2012. Online. Disponível em: <http://www.bndespar.gov.br/SiteBNDES/export/sites/default /bndes_pt/Galerias/Arquivos/conhecimento/bnset/set3512.pdf> Acesso em 24 ago. 2015.

SILVA, N. B. da; GURGEL, H. C. B; SANTANA M. D.; Histologia do sistema digestório de Saguiru, Steindachnerina notonota (MIRANDA RIBEIRO, 1937) (PISCES, CURIMATIDAE), do rio Ceará Mirim, Rio Grande do Norte, Brasil. Boletim do Instituto de Pesca, v.31, n.1, p.1 - 8, 2005. 